\title{
Impact of contingency manipulations on accessory stimulus effects
}

\author{
ANDrea Kiesel \\ Julius-Maximilians-Universität, Würzburg, Germany \\ AND \\ JEFF MiLLeR \\ University of Otago, Dunedin, New Zealand
}

\begin{abstract}
Accessory tone stimuli facilitate response performance despite being irrelevant for the current task. In order to investigate which processes are affected by accessory stimuli, we presented accessory tones in a simple response time (RT) task while varying the contingencies between accessory stimulation and either responses (Experiment 1) or stimulus conditions (Experiment 2). Accessory tones speeded up responding to a larger degree when they were conjointly presented within go compared with no-go trials. In contrast, contingency variation with stimulus conditions did not alter the impact of accessory stimuli. Additionally, accessory tones increased response force. Thus, we conclude that in simple RT tasks accessory tones influence response-related stages such as response selection and response execution rather than perceptual processes.
\end{abstract}

One of the oldest questions in psychology is how information from different sensory modalities is combined. For example, Todd (1912) presented combinations of light, tone, and electrical shock stimuli, instructing participants to respond whenever they detected any stimulus. Response times (RTs) were reduced when bimodal rather than unimodal stimuli were presented. Such intersensory facilitation effects are quite robust, and they have been replicated in many different settings. For example, intersensory facilitation has been reported in tasks such as Todd's, in which participants must respond to stimuli from any modality (e.g., Diederich \& Colonius, 2004; Gondan, Niederhaus, Rösler, \& Röder, 2005; Hershenson, 1962; Miller, 1991). Intersensory facilitation has also been reported when instructionally irrelevant accessory stimuli on one modality (i.e., stimuli to which participants need not respond) are presented simultaneously with relevant target stimuli on another modality, especially when the irrelevant accessories are auditory stimuli (Bernstein, 1970; Doyle \& Snowden, 2001). Finally, intersensory facilitation has also been found when auditory warning signals are presented prior to visual target stimuli (FernandezDuque \& Posner, 1997; Sanders, 1980; Ulrich \& Mattes, 1996; Zeigler, Graham, \& Hackley, 2001).

\section{ACCESSORY STIMULATION}

Intersensory facilitation seems to be especially surprising when the accessory stimulus is irrelevant for the task that participants must perform. For example, consider a recent task used by Hackley and Valle-Inclán (1999). In this study, participants were asked to indicate by pressing a left or a right response key whether the letter $\mathrm{S}$ or $\mathrm{T}$ was presented. The target letters were presented in different colors and one of the colors (e.g., violet) instructed participants not to respond in this trial. In this choice/no-go paradigm, accessory tone stimuli were presented in $50 \%$ of all trials. Even though the tone stimuli were not related to any visual stimulus feature and were thus completely irrelevant for the task, participants responded $34 \mathrm{msec}$ faster in trials with a tone than in those without one.

Despite the many studies of intersensory facilitation by accessory stimuli (e.g., Bernstein, 1970; Bernstein, Rose, \& Ashe, 1970; Bertelson \& Tisseyre, 1969; Dufft \& Ulrich, 1999; Keuss, Van der Zee, \& Van den Bree, 1990; Nakano, 1997, 2002; Nickerson, 1973; Schmidt, Gielen, \& Van den Heuvel, 1984; Stahl \& Rammsayer, 2005), it is still unclear how the accessory stimulus facilitates responding. One of the major debates concerns the issue of which processing stages are influenced by an accessory tone (Hackley \& Valle-Inclán, 1998, 1999, 2003; Miller, Franz, \& Ulrich, 1999; Nakano, 2002; Stahl \& Rammsayer, 2005). In principle, at least three different positions can be identified.

First, there is evidence that irrelevant auditory stimuli alter perception processes; for example, the perceived intensity of a visual stimulus is affected by concurrent auditory stimulation (Stein, London, Wilkinson, \& Price, 1996). Likewise, the perceived number of visual events is biased by the number of concurrently presented tones

A. Kiesel, kiesel@psychologie.uni-wuerzburg.de 
(Shams, Kamitani, \& Shimojo, 2000). Second, Hackley and Valle-Inclán $(1998,1999)$, having found that the onset of the lateralized readiness potential (LRP) occurs earlier with irrelevant tone signals than without them whereas the temporal extension of the LRP remains stable, claimed that accessory stimuli influence early response selection processes. Similarly, Posner, Nissen, and Klein (1976; see also Nickerson, 1973) suggested that accessory stimuli speed up response selection processes. However, they claimed that faster responding because of accessory stimulation always goes along with higher error rates, because the arousing effect causes a participant "to respond sooner to the information building up in his memory system" (Posner et al., 1976, p. 161). Third, accessory stimuli might also influence motor output processes, because it has been shown that auditory stimuli affect not only response speed but also response force (Miller et al., 1999; Stahl \& Rammsayer, 2005).

In order to investigate further the mechanism(s) affected by accessory stimuli, we conducted two experiments varying the contingencies between accessory stimulation and either responses (Experiment 1) or stimulus conditions (Experiment 2). The logic behind the contingency manipulation is that the accessory stimulus effect should be modulated by contingencies affecting the same stage as the accessory stimulus. For example, if perceptual processes are influenced by irrelevant ${ }^{1}$ accessory stimuli, the accessory effect should be sensitive to the joint probability of these stimuli and particular target stimuli. Specifically, an accessory stimulus ought to facilitate perception, especially for a particular target with which it often co-occurs. On the other hand, if response selection or response production processes are influenced by accessory stimuli, the accessory effect should be sensitive to the joint probability of tones and responses. Again, an accessory stimulus should facilitate responding more when it usually occurs together with the go response than when it usually occurs with the no-go response. Finally, if accessory stimuli influence both perception and responses, then both types of contingencies should modulate the accessory effect.

\section{Simple RT Tasks}

In order to investigate the impact of contingency manipulations on accessory stimulus effects, we used a visual simple RT task with target stimuli presented to the left of fixation, to the right of fixation, or both-a task that has often been studied to learn about redundancy gain in divided attention tasks (e.g., Corballis, 2002; Gondan et al., 2005; Miller, 1982, 1986; Mordkoff \& Miller, 1993; Schröger \& Widmann, 1998). In single-target trials, a single rectangle was presented either to the left or to the right of fixation; in redundant-target trials, both rectangles were presented. Participants were asked to make a righthand keypress response as quickly as possible when any visual stimulus appeared, so there was only one response alternative. Finally, in catch or no-go trials, no visual stimulus was presented and participants were instructed to withhold the response. Typically, within this simple RT task, participants respond faster to redundant targets than to single targets, a phenomenon called redundancy gain.
We decided to use a simple RT task for several reasons: First, accessory stimulation has generally been shown to be more effective in simple RT than in choice RT tasks (e.g., Nakano, 1997), and accessory stimulus effects have been shown to be quite strong in this particular simple RT task even in the absence of contingencies (Miller \& Van Nes, 2007). Thus, differences in effect size due to contingency variations might be easier to obtain. Second, this task has the minimal structure needed to vary whether the accessory stimulation is correlated with the response (Experiment 1) or with the stimuli (Experiment 2), because it has two response conditions (go and no-go) and two target conditions (single- and redundant-target trials). Third, it may also be of interest within the literature on redundancy gain to determine whether different types of contingencies influence the speedup in responses to redundant targets rather than single targets.

\section{Response Force}

In the present study, response force was measured in addition to response speed (i.e., RT). Response force has been shown to be a useful supplementary measure in RT experiments, because it provides additional ways of testing chronometric theories (e.g., Abrams \& Balota, 1991; Balota \& Abrams, 1995; Giray \& Ulrich, 1993; Ulrich, Mattes, \& Miller, 1999; Ulrich, Rinkenauer, \& Miller, 1998). As already mentioned, for example, the finding that accessory stimuli increase response force suggests that at least some of their effects involve motor output processes (e.g., Miller et al., 1999; Stahl \& Rammsayer, 2005). Furthermore, there are also dissociable effects on RTs and response force. For example, when varying the time interval between an accessory stimulus and a target stimulus in separate blocks, RTs increase with longer intervals but there is no impact on response force (Mattes, Ulrich, \& Miller, 1997). Thus, we were interested in whether manipulating contingencies of accessory stimulation with either responses (Experiment 1) or with stimulus conditions (Experiment 2) would modulate the effects of accessory stimuli on RT and force in the same or in different ways.

\section{EXPERIMENT 1}

Participants performed a standard simple RT task. They were asked to respond as quickly as possible when a visual stimulus - a rectangle - appeared to either the left or the right of fixation (single-target conditions) or when both rectangles appeared (redundant-target condition). In trials without visual targets (called no-go or catch trials), they were told not to respond. Simultaneously with target presentation, or at the same point in time in no-go (i.e., catch) trials without targets, an irrelevant tone stimulus (the accessory stimulus) could occur. In Experiment 1, we varied the contingency of accessory stimulation with the response. For one group of participants, the accessory tone was presented in $75 \%$ of all go trials (i.e., in single- and in redundant-target trials), but only in $25 \%$ of all no-go (i.e., catch) trials. For another group of participants this ratio was reversed. The exact numbers of trials per condition in each block are listed in Table 1. 
Table 1

Trial Frequencies per Block in Experiment 1, As a Function of Condition, Irrelevant Tone (IT), and Target

\begin{tabular}{|c|c|c|c|c|}
\hline \multirow[b]{2}{*}{ Target } & \multicolumn{2}{|c|}{$\begin{array}{l}\text { Condition I: } \\
\text { Tone Frequent } \\
\text { With Go }\end{array}$} & \multicolumn{2}{|c|}{$\begin{array}{l}\text { Condition II: } \\
\text { Tone Frequent } \\
\text { With No-Go }\end{array}$} \\
\hline & $\begin{array}{c}\text { IT } \\
\text { Present }\end{array}$ & $\begin{array}{c}\text { IT } \\
\text { Absent }\end{array}$ & $\begin{array}{c}\text { IT } \\
\text { Present }\end{array}$ & $\begin{array}{c}\text { IT } \\
\text { Absent }\end{array}$ \\
\hline None & 12 & 36 & 36 & 12 \\
\hline Left & 9 & 3 & 3 & 9 \\
\hline Right & 9 & 3 & 3 & 9 \\
\hline Redundant & 18 & 6 & 6 & 18 \\
\hline
\end{tabular}

\section{Method}

Participants. Participants were 24 right-handed volunteers (11 men and 13 women; age range, $18-32$ years). They were recruited on the campus of the University of Otago and each received NZ\$9.50 in return for participation. Each participant attended a single experimental session lasting approximately $60 \mathrm{~min}$. Data of 2 participants had to be replaced because 1 participant stopped responding in the last two blocks and another committed too many errors in no-go trials.

Apparatus and Stimuli. Stimulus presentation and response recording were accomplished by a PC-compatible computer. The imperative stimuli were white rectangles $\left(1.7^{\circ}\right.$ high $\times 1.5^{\circ}$ wide at the viewing distance of $50 \mathrm{~cm}$ ) presented on the dark background of a standard monitor. Each rectangle was presented $6.8^{\circ}$ to the left or to the right of the fixation point. The irrelevant tone signal was presented binaurally over headphones at $525 \mathrm{~Hz}$ and approximately $70 \mathrm{~dB}$.

Responses were recorded on a force-sensitive key similar to a telegraph key. The key was constructed from a leaf spring $(140 \times$ $20 \times 2 \mathrm{~mm}$ ) with one end of the spring fixed in a pedestal and the other end extending toward the participant at a height of approximately $7 \mathrm{~mm}$ above a base on which the right forearm rested. Participants responded by pressing the free end of the leaf spring with a quick finger flexion. A cutout from the base allowed essentially unlimited downward movement. Strain gauges (Type 6 / 120 LY 41, manufactured by Hottinger Baldwin Messtechnik, Darmstadt, Germany) were attached near the fixed end of the leaf spring, so force applied to the free end was reflected in an analog signal with a resolution of approximately $2.8 \mathrm{mN}$. A force of $15 \mathrm{~N}$ bent the free end of the key by approximately $2 \mathrm{~mm}$. The force signal from the key was digitized at $250 \mathrm{~Hz}$ in each trial, starting $200 \mathrm{msec}$ before the onset of the stimuli and continuing for $1.7 \mathrm{sec}$. At the beginning of testing, the force key was calibrated for each participant, using a 50-g weight.

Procedure. Each trial started with the presentation of a plus sign in the center of the screen to serve as a fixation point and a visual warning signal. The visual and auditory stimuli were presented $1,000 \mathrm{msec}$ after the onset of the plus sign as appropriate to the type of trial; that is, either no visual stimulus appeared, or a single target rectangle appeared to the left or to the right of fixation, or two target rectangles appeared to the left and to the right of fixation. Likewise, a tone was presented, or not. The visual target stimuli remained on the screen until at least $100 \mathrm{cN}$ of response force was reached. The tone was presented for $150 \mathrm{msec}$. Responses were recorded in a time window up to $1,500 \mathrm{msec}$ starting from stimulus onset. In cases of errors - that is, omission or false alarms - feedback was given for $2.5 \mathrm{sec}$ after the response window had passed (omissions) or after the response was detected (false alarms). The fixation point appeared to begin the next trial approximately $750 \mathrm{msec}$ after the correct response (go trials), after the end of the response window (no-go trials), or after the error feedback in any error trial.

Participants were instructed to respond as quickly as possible to the onset of any rectangle and not to respond if no rectangle was presented. They were instructed that tones would also occur in some trials, but that these were irrelevant and should be ignored. They were not informed about the contingency manipulation. Prior to the experiment, they were given some practice to learn the minimum amount of force $(100 \mathrm{cN})$ that would be registered as response. Half of this force (i.e., $50 \mathrm{cN}$ ) was defined as the criterion level for response onset for the purposes of measuring RT.

Each participant performed eight blocks with 96 trials. Within each block, there were eight possible stimulus conditions that were presented according to the trial frequencies indicated in Table 1. Half of the 24 participants were tested with accessory stimulation frequent in go trials (Condition I); the other 12 participants were tested with accessory stimulation frequent in no-go trials (Condition II).

\section{Results}

For each trial, RT was scored as the latency at which the force measured by the response key reached the criterion of $50 \mathrm{cN}$, and peak force (PF) was scored as the maximum level of force output produced during the 1,500-msec response window.

Errors and outliers. The averages of mean error percentages are shown separately for Conditions I (tone frequent in go) and II (tone frequent in no-go) in Table 2. We conducted no statistical analysis, because the error percentages were too small.

Errors and trials with outlier RTs less than $100 \mathrm{msec}$ $(0.03 \%)$ were excluded from the analysis. Responses were only recorded in a time window up to $1,500 \mathrm{msec}$ after stimulus onset; trials with RTs longer than 1,500 msec were therefore counted as omission errors. For the remaining trials, RTs and PFs were averaged for each participant and each combination of the factors target (left, right, or redundant) and irrelevant tone (present or absent). The averages of these means across participants are shown separately for Conditions I (tone frequent in go) and II (tone frequent in no-go) in Table 3.

Frequency effects. To assess the impact of the frequency manipulation, separate ANOVA were carried out on RT and PF with the between-subjects factor of frequency condition (tone frequent with go or tone frequent with no-go) and with the within-subjects factors of target (left, right, or redundant) and irrelevant tone (present or absent). In the ANOVA on RT, the effect of target was highly significant $\left[F(2,44)=32.09, M S_{\mathrm{e}}=324.42, p<\right.$ $.001]$. Participants responded faster in the redundant-target condition $(330 \mathrm{msec})$ than in the single-target conditions (left, $357 \mathrm{msec}$; right, $353 \mathrm{msec}$ ), reflecting redundancy gain. Furthermore, the effect of irrelevant tone was highly significant $\left[F(1,22)=95.15, M S_{\mathrm{e}}=1,258.7, p<.001\right]$.

Table 2

Mean Error Percentages As a Function of Frequency Condition, Irrelevant Tone (IT), and Target

\begin{tabular}{|c|c|c|c|c|}
\hline \multirow[b]{2}{*}{ Target } & \multicolumn{2}{|c|}{$\begin{array}{l}\text { Condition I: } \\
\text { Tone Frequent } \\
\text { With Go }\end{array}$} & \multicolumn{2}{|c|}{$\begin{array}{l}\text { Condition II: } \\
\text { Tone Frequent } \\
\text { With No-Go }\end{array}$} \\
\hline & $\begin{array}{c}\text { IT } \\
\text { Present }\end{array}$ & $\begin{array}{c}\text { IT } \\
\text { Absent }\end{array}$ & $\begin{array}{c}\text { IT } \\
\text { Present }\end{array}$ & $\begin{array}{c}\text { IT } \\
\text { Absent }\end{array}$ \\
\hline None & 4.2 & 0.0 & 0.6 & 0.1 \\
\hline Left & 0.1 & 1.4 & 0.0 & 0.5 \\
\hline Right & 0.1 & 0.4 & 0.0 & 0.1 \\
\hline Redundant & 0.2 & 0.0 & 0.0 & 0.0 \\
\hline
\end{tabular}


Table 3

Mean Response Time (RT, in Milliseconds) and Peak Force (PF, in

Centinewtons) As a Function of Frequency Condition, Irrelevant Tone (IT), and Target

\begin{tabular}{|c|c|c|c|c|c|c|c|c|}
\hline \multirow[b]{3}{*}{ Target } & \multicolumn{4}{|c|}{$\begin{array}{c}\text { Condition I: } \\
\text { Tone Frequent With Go }\end{array}$} & \multicolumn{4}{|c|}{$\begin{array}{c}\text { Condition II: } \\
\text { Tone Frequent With No-Go }\end{array}$} \\
\hline & \multicolumn{2}{|c|}{ IT Present } & \multicolumn{2}{|c|}{ IT Absent } & \multicolumn{2}{|c|}{ IT Present } & \multicolumn{2}{|c|}{ IT Absent } \\
\hline & RT & $\mathrm{PF}$ & RT & $\mathrm{PF}$ & RT & $\overline{\mathrm{PF}}$ & RT & $\mathrm{PF}$ \\
\hline Left & 325 & 1,015 & 424 & 1,004 & 324 & 937 & 354 & 91 \\
\hline Right & 329 & 1,013 & 417 & 1,006 & 321 & 919 & 344 & \\
\hline Redundant & 306 & 1,012 & 392 & 1,014 & 300 & 944 & 321 & 913 \\
\hline Redundancy gain & 21 & -2 & 28 & 9 & 23 & 16 & 28 & \\
\hline
\end{tabular}

Note-For RT, redundancy gain was measured as the average of the mean for left and right targets minus the mean for redundant targets. For PF, the subtraction was performed in the opposite order.

Responses were $57 \mathrm{msec}$ faster with an accessory tone than without one. The impact of the accessory tone differed depending on the frequency conditions $[F(1,22)=$ $\left.31.70, M S_{\mathrm{e}}=1,258.7, p<.001\right]$. When the tone was frequently presented in go trials, participants responded $91 \mathrm{msec}$ faster with an accessory stimulus than without one, whereas this RT difference amounted to only $24 \mathrm{msec}$ when the tone was frequently presented in no-go trials. No other effects were significant $(p \mathrm{~s}>.12)$. In particular, redundancy gain did not vary as a function of either the presence/absence of a tone $(p>.13)$ or the tone $\times$ frequency condition interaction $(p>.91)$.

The same ANOVA on PF revealed a significant effect of irrelevant tone $\left[F(1,22)=10.42, M S_{\mathrm{e}}=666.36, p<\right.$ $.05]$, as responses were $14 \mathrm{cN}$ more forceful in trials with an accessory stimulus than without one. Furthermore, the interaction between the factors irrelevant tone and frequency condition approached significance $[F(1,22)=$ 4.03, $\left.M S_{\mathrm{e}}=666.36, p<.057\right]$. Participants with frequent tone presentation in no-go trials tended to respond more forcefully with an accessory stimulus $(934 \mathrm{cN})$ than without one $(911 \mathrm{cN})$, whereas response force was similar with $(1,013 \mathrm{cN})$ and without $(1,008 \mathrm{cN})$ an accessory stimulus for participants with frequent tone presentation in go trials. No other effects were significant ( $p s>.24)$.

Analyses of RT were carried out to test the race model inequality (for an exact description of the procedure see Ulrich, Miller, \& Schröter, 2007; for bias corrections, see Kiesel, Miller, \& Ulrich, 2007). The race model inequality was not violated in any condition, so the redundancy gain observed in this experiment could be consistent with race models as well as with coactivation models. Furthermore, the fact that tests of the race model yielded the same outcome with and without accessory stimuli provides further evidence that redundancy gain is not modulated by these stimuli.

\section{Discussion}

First, we replicated the standard result concerning accessory stimulation: Participants responded more rapidly when the irrelevant tone was present than when it was absent. Furthermore, response force was in line with the RT data, because participants also responded more forcefully with a tone than without one. Thus, we also replicated the recent findings of Miller et al. (1999; see also Stahl \& Rammsayer, 2005) showing that accessory stimuli affect response output patterns.

Second and more importantly, the contingency manipulation had a strong impact on the effects of accessory stimulation. The accessory tone speeded up responding to a much larger degree when it was presented more frequently in go trials than when it was presented more frequently in no-go trials. This shows that the effectiveness of an accessory stimulus depends at least in part on the extent to which it is associated with the response that is required, and thereby supports the idea that at least a part of the effectiveness of accessory stimulation is related to response processes.

Interestingly, the accessory stimulus tended to increase response force, especially when it was infrequent in go trials. This pattern can be explained in terms of the finding that low-probability responses are executed more forcefully than are high-probability responses (e.g., Mattes et al., 1997), simply on the basis of the assumption that the response system is sensitive to the conditional probability of responding as indicated by the presence versus the absence of the accessory stimulus. To account for the finding that low-probability responses were executed more slowly and more forcefully, Mattes and colleagues extended the "motor readiness" model proposed by Näätänen (1971; see also Niemi \& Näätänen, 1981). This model assumes that an overt response is triggered when motor readiness exceeds a criterion called the "motor-action limit," and that the actual response force increases with the degree of motor readiness at the point of initiating the response. The latency of responding to a response signal is determined by the distance between the level of motor readiness and the motor-action limit: The smaller the distance, the faster the response. When participants prepare to respond because they expect a response signal, they increase motor readiness close to the motor-action limit. Mattes et al. proposed that detection of a response signal causes a variable increment, depending on the distance between the level of motor readiness and the motor-action limit. If this distance is small, the increment to reach the limit is small. Conversely, if the distance is large, a large increment is necessary to reach the limit. Consequently, participants respond faster when they are prepared to respond (small 
distance) than when they are unprepared (large distance). Because the motor system is inherently noisy, the actual increment in motor activation is larger than the minimum needed to reach the limit; that is, because of noise in the system, some overshoot is necessary to ensure that motor activation does exceed the motor-action limit. This overshoot is assumed to be larger if the necessary increment is larger, because larger increments are more variable. As a result, response force is larger when participants have not been prepared to respond (large increment) than when they have been prepared (small increment). On this view, detection of the accessory stimulus would cause a rapid response-level upward or downward adjustment of the probability of the go response, depending on the stimulus-response contingency to which the participant was assigned. If the accessory stimulus suggested that the go response was likely (Condition I), go response probability would be adjusted upward, leading to faster but less forceful responses. Conversely, if the accessory stimulus suggested that the go response was unlikely (Condition II), go response probability would be adjusted downward, leading to slower and more forceful responses. Thus, both the RT and PF results can be explained in terms of a single response-level adjustment on the basis of the accessory stimulus.

With respect to the issue of redundancy gain, we replicated the standard finding within divided attention research: Participants responded more rapidly to two redundant targets than to one single target. Interestingly, however, redundancy gain did not depend on either the presence/absence of the accessory stimuli or on the contingency manipulations.

Before discussing the possible effects of accessory stimuli in more detail, we first want to gain a more complete picture of the way in which contingency manipulations influence the effects of accessory stimulation.

\section{EXPERIMENTS 2A AND 2B}

In Experiment 2, the contingency between accessory stimulation and stimulus conditions was varied without introducing any contingency between accessory stimulation and the response. For one group of participants, the accessory tone was presented in 20 out of 24 (i.e., $83.3 \%$ ) of the redundant-target trials, but in only 4 out of 24 (i.e., $16.7 \%$ ) of the single-target trials. For another group of participants this ratio was reversed. Thus, for one group of participants the accessory stimulus was presented more frequently in redundant-target trials, whereas for another group of participants, the accessory tone was presented more frequently in single-target trials. For both of these groups, though, the probability of accessory stimulation in go and no-go trials was kept constant, with an accessory tone presented in $50 \%$ of all go trials and $50 \%$ of all no-go trials. The exact numbers of trials per block per condition are listed in Table 4.

The procedure of Experiment 2A was closely parallel to that of Experiment 1: Participants performed one session with eight blocks of either Condition I or Condition II. The frequency manipulation, accordingly, was varied between
Table 4

Trial Frequencies per Block in Experiment 2, As a Function of Condition, Irrelevant Tone (IT), and Target

\begin{tabular}{lccccc}
\hline & \multicolumn{2}{c}{$\begin{array}{c}\text { Condition I: } \\
\text { Tone Frequent With } \\
\text { Redundant Target }\end{array}$} & & \multicolumn{2}{c}{$\begin{array}{c}\text { Condition II: } \\
\text { Tone Frequent With } \\
\text { Single Target }\end{array}$} \\
\cline { 2 - 3 } \cline { 5 - 6 } Target & IT & IT & & IT & IT \\
None & 12 & Absent & & Present & Absent \\
Left & 2 & 12 & & 12 & 12 \\
Right & 2 & 10 & & 10 & 2 \\
Redundant & 20 & 10 & & 10 & 2 \\
\hline
\end{tabular}

subjects. In Experiment 2B, each participant gained much more training and performed both frequency conditions over four sessions with eight blocks each, so the frequency condition was varied within subjects.

\section{Method}

Participants. Participants in Experiment 2A were 60 students in psychology at the University of Otago who took part in the experiment in partial fulfillment of a course requirement. There were 13 men and 47 women (age range, 18-27 years). Five of the participants were left-handed. Each participant attended a single experimental session lasting approximately $45 \mathrm{~min}$. In Experiment 2B, 9 women students in psychology (age range, 19-32 years) took part in exchange for payment. Each participant attended eight single sessions lasting approximately $45 \mathrm{~min}$. None of the participants had participated in Experiment 1.

Apparatus, Stimuli, and Procedure. The apparatus, stimuli, and procedure were the same as those used in Experiment 1, except for the trial frequencies. In Experiment 2A, each participant performed eight blocks with 72 trials per block. The eight possible stimulus conditions were presented according to the trial frequencies indicated in Table 4. Thirty participants were tested with accessory stimulation frequent in redundant-target trials (Condition I), and the other 30 participants were tested with accessory stimulation frequent in single-target trials (Condition II). In Experiment 2B, each participant performed four sessions with eight blocks in each frequency condition. Four participants started with Condition I in Sessions 1-4 and then performed Condition II in Sessions 5-8. For the other 5 participants, this order was reversed.

\section{Results}

The methods of analysis were closely parallel to those of Experiment 1.

Errors and outliers. The averages of mean error percentages separately for the conditions tone frequent in go and tone frequent in no-go for Experiments $2 \mathrm{~A}$ and $2 \mathrm{~B}$ are shown in Table 5. Again, no statistical analysis was conducted, because error percentages were too small.

Errors and outliers with RTs less than $100 \mathrm{msec}(.08 \%$ for Experiment $2 \mathrm{~A}$ and $.04 \%$ for Experiment $2 \mathrm{~B}$ ) were excluded from further analysis. Mean RTs and PFs for each combination of the factors frequency condition (tone frequent in redundant- or in single-target trials), target (left, right, or redundant), and irrelevant tone (present or absent) are shown in Table 6.

Frequency effects. The data of Experiment 2A were subjected to separate ANOVA for RT and PF with the between-subjects factor of frequency condition (tone frequent with single target or tone frequent with redundant target) and with the within-subjects factors of target (left, 
Table 5

Mean Error Percentages As a Function of Frequency Condition, Irrelevant Tone (IT), and Target for Experiments $2 A$ and $2 B$

\begin{tabular}{|c|c|c|c|c|}
\hline \multirow[b]{2}{*}{ Target } & \multicolumn{2}{|c|}{$\begin{array}{l}\text { Condition I: } \\
\text { Tone Frequent With } \\
\text { Redundant Target }\end{array}$} & \multicolumn{2}{|c|}{$\begin{array}{c}\text { Condition II: } \\
\text { Tone Frequent With } \\
\text { Single Target }\end{array}$} \\
\hline & IT Present & IT Absent & IT Present & IT Absent \\
\hline \multicolumn{5}{|c|}{ Experiment 2A } \\
\hline None & 3.5 & 0.1 & 3.2 & 0.1 \\
\hline Left & 0.4 & 0.5 & 0.2 & 0.6 \\
\hline Right & 0.2 & 0.4 & 0.1 & 0.4 \\
\hline Redundant & 0.2 & 0.5 & 0.2 & 0.2 \\
\hline \multicolumn{5}{|c|}{ Experiment 2B } \\
\hline None & 2.3 & 0.1 & 3.4 & 0.0 \\
\hline Left & 0.0 & 0.4 & 0.0 & 0.5 \\
\hline Right & 0.0 & 0.2 & 0.1 & 0.2 \\
\hline Redundant & 0.1 & 0.1 & 0.0 & 0.0 \\
\hline
\end{tabular}

right, or redundant) and irrelevant tone (present or absent). In the ANOVA on RT, redundancy gain was observed, since participants responded faster in the redundant-target condition $(305 \mathrm{msec})$ than in the single-target conditions [left, $338 \mathrm{msec}$; right, $328 \mathrm{msec} ; F(2,116)=108.68, M S_{\mathrm{e}}=$ $313.53, p<.001]$. Furthermore, the accessory tone stimulus speeded up responding, with mean RTs of $350 \mathrm{msec}$ without a tone but $297 \mathrm{msec}$ with one $[F(1,58)=320.99$, $\left.M S_{\mathrm{e}}=804.68, p<.001\right]$. The interaction between target and irrelevant tone was significant $[F(2,116)=3.25$, $\left.M S_{\mathrm{e}}=246.73, p<.05\right]$, reflecting larger redundancy gain in trials without tones $(32 \mathrm{msec}$ for the difference between the redundant-target condition and the average of the two single-target conditions) compared with trials with tones (24 msec). Neither the main effect of frequency condition nor any interaction with frequency condition reached significance $(p s>.56)$.

The same ANOVA on PFs reflected a significant effect of redundancy gain $\left[F(2,116)=8.91, M S_{\mathrm{e}}=625.50\right.$, $p<.001]$, since responses to redundant targets $(652 \mathrm{cN})$ were more forceful than to single targets (left: $641 \mathrm{cN}$; right: $640 \mathrm{cN}$ ). Likewise, participants responded more forcefully in trials with tones $(653 \mathrm{cN})$ than without tones $(637 \mathrm{cN})\left[F(1,58)=16.65, M S_{\mathrm{e}}=1,404.0, p<.001\right]$. Again, neither the effect of frequency condition nor any interaction reached significance $(p s>.24)$.

For Experiment 2B, separate ANOVA were carried out on RT and PF with the within-subjects factors of frequency condition (tone frequent with single target or tone frequent with redundant target), session (1-4 within each frequency condition), target (left, right, or redundant), and irrelevant tone (present or absent). The ANOVA on RTs indicated significant redundancy gain, as participants responded faster for redundant targets $(277 \mathrm{msec})$ than for single targets (left, $302 \mathrm{msec}$; right, $295 \mathrm{msec})[F(2,16)=$ $\left.40.00, M S_{\mathrm{e}}=580.94, p<.001\right]$. Furthermore, participants responded faster in trials with tones $(273 \mathrm{msec})$ than without tones $(309 \mathrm{msec})\left[F(1,8)=32.09, M S_{\mathrm{e}}=4,423.8, p<\right.$ $.001]$. And finally, RTs decreased over sessions (mean RT amounted to $311 \mathrm{msec}$ in Session 1, $292 \mathrm{msec}$ in Session 2, $280 \mathrm{msec}$ in Session 3, and $282 \mathrm{msec}$ in Session 4); that is, participants responded faster the more practice they had in each frequency condition $\left[F(3,24)=24.58, M S_{\mathrm{e}}=897.17\right.$, $p<.001]$. No other effects were significant $(p \mathrm{~s}>.20)$.

In the parallel ANOVA on PF, responses were more forceful to redundant targets $(859 \mathrm{cN})$ than to single targets (left, $845 \mathrm{cN}$; right, $849 \mathrm{cN})\left[F(2,16)=6.35, M S_{\mathrm{e}}=\right.$ $1,067.2, p<.05]$, and responses were more forceful with the tone $(865 \mathrm{cN})$ than without it $(837 \mathrm{cN})[F(1,8)=8.20$, $\left.M S_{\mathrm{e}}=10,624.5, p<.05\right]$. No other effect reached significance $(p s>.22)$.

Again, analyses of RT were carried out to test the race model inequality. There were no violations of the race model inequality in any conditions, which further supports the finding that redundancy gain is not modulated by accessory stimuli.

Table 6

Mean Response Time (RT, in Milliseconds) and Peak Force (PF, in Centinewtons) As a Function of Frequency Condition, Irrelevant Tone (IT), and Target for Experiments $2 A$ and $2 B$

\begin{tabular}{|c|c|c|c|c|c|c|c|c|}
\hline \multirow[b]{3}{*}{ Target } & \multicolumn{4}{|c|}{$\begin{array}{c}\text { Condition I: } \\
\text { Tone Frequent With } \\
\text { Redundant Target }\end{array}$} & \multicolumn{4}{|c|}{$\begin{array}{c}\text { Condition II: } \\
\text { Tone Frequent With } \\
\text { Single Target }\end{array}$} \\
\hline & \multicolumn{2}{|c|}{ IT Present } & \multicolumn{2}{|c|}{ IT Absent } & \multicolumn{2}{|c|}{ IT Present } & \multicolumn{2}{|c|}{ IT Absent } \\
\hline & RT & PF & RT & $\mathrm{PF}$ & RT & $\mathrm{PF}$ & RT & $\mathrm{PF}$ \\
\hline \multicolumn{9}{|c|}{ Experiment 2A } \\
\hline Left & 305 & 618 & 362 & 606 & 313 & 677 & 372 & 664 \\
\hline Right & 296 & 623 & 353 & 601 & 304 & 676 & 357 & 661 \\
\hline Redundant & 279 & 631 & 325 & 617 & 284 & 691 & 333 & 671 \\
\hline Redundancy gain & 21 & 10 & 33 & 14 & 25 & 15 & 32 & 9 \\
\hline \multicolumn{9}{|c|}{ Experiment 2B } \\
\hline Left & 286 & 912 & 322 & 884 & 279 & 807 & 320 & 778 \\
\hline Right & 281 & 920 & 317 & 885 & 274 & 807 & 307 & 782 \\
\hline Redundant & 263 & 928 & 296 & 900 & 256 & 815 & 294 & 791 \\
\hline Redundancy gain & 19 & 12 & 24 & 16 & 21 & 8 & 20 & 11 \\
\hline
\end{tabular}

Note-For RT, redundancy gain was measured as the average of the mean for left and right targets minus the mean for redundant targets. For PF, the subtraction was performed in the opposite order. 


\section{Discussion}

As in Experiment 1, a strong accessory stimulus effect was again observed, with participants responding faster in trials with an accessory tone than in those without one. Again, these findings were also mirrored in response force, as participants also responded more forcefully with an accessory stimulus than without one.

The main result of this experiment is that varying the contingency of accessory stimulation with stimulus conditions had no impact on the size of the accessory stimulus effect. On average across groups, the accessory effect was $43 \mathrm{msec}$ for the stimuli with which the accessories were often presented and $45 \mathrm{msec}$ for the stimuli with which the accessories were rarely presented. Thus, accessories do not seem to facilitate detection of the stimuli with which they are often presented, suggesting that there is relatively little if any accessory-based adjustment within the perceptual detection system. One might speculate that effects of stimulus contingencies are more difficult to find because it takes longer for participants to acquire them. However, we can rule out this suspicion, because in Experiment 2B participants practiced each frequency condition for four sessions, yet the frequency manipulation still had no impact on the effectiveness of accessory stimulation. ${ }^{2}$ Thus, the lack of effect provides evidence against the assumption that accessory stimuli influence perceptual processes.

As in Experiment 1, the redundant-targets effect was observed for both RT and force. This effect was not modulated by contingency; this is not surprising, given that contingency did not modulate the effect of accessory stimuli. In Experiment 2A, the redundant-target effect on RT was slightly smaller in trials with accessory tones than it was in trials without accessory tones. However, it seems that this effect is rather small and hard to replicate, as it was observed in neither Experiment 2B nor in Experiment 1. We further discuss this topic below.

\section{GENERAL DISCUSSION}

In the present study, we investigated the effect of accessory stimulation in simple RT tasks where the irrelevant accessory tones were presented more frequently with certain responses (go vs. no-go, Experiment 1) or more frequently with certain stimulus types (single vs. redundant targets, Experiment 2). The results are clear. Varying the contingency of accessory stimulation with responses substantially modulates the effect of accessory stimulation. In contrast, varying the contingency of accessory stimulation with stimulus types has no impact on the effect of accessory stimulation.

Our results are in line with the assumption that accessory stimuli influence response processes both in response selection stages, as suggested by Hackley and Valle-Inclán $(1998,1999)$ and Posner et al. (1976), and in motor output processes. First, varying the contingency of accessory stimuli with go and no-go responses modulated strongly the facilitation effect on RT. Thus, participants are clearly quite sensitive to the contingencies between accessory stimuli and response conditions. Second, response force was also sensitive to these contingencies, demonstrating that irrelevant tones also have an influence at the level of motor output patterns.

In contrast, contingent presentation of the irrelevant tones with either the redundant- or the single-target condition did not alter the impact of accessory stimulation. Thus, there is no hint that the accessory tone might influence perceptual processes in this simple setting. Of course, this does not rule out the possibility that accessory auditory stimulation influences perception in more difficult settings with more ambiguous visual stimuli (e.g., Shams et al., 2000; Stein et al., 1996). However, when the stimulus setting and the responses afforded by the stimuli are clear and without ambiguity, perceptual processing of visual targets seems to be uninfluenced by accessory stimulation.

This pattern of results rules out one of the three modes of operation for accessory stimuli that have been described in the introduction. Our evidence suggests that accessory stimuli in a simple RT task do not influence perceptual processes but facilitate responding because of their impact on response selection and/or response execution stages.

In order to elaborate further on the nature of this response-related impact, it is interesting to note that accessory stimuli still facilitated responding to some degree when compared with no-accessory trials, even when such stimuli were usually presented in no-go trials. For participants experiencing accessories mostly in no-go trials in Experiment 1, for example, responses were $24 \mathrm{msec}$ faster with an accessory tone than without one. Thus, accessory tones still produced a net facilitation effect in these trials, even though that facilitation was smaller than would be expected for tones not associated with either response category (e.g., an effect of $53 \mathrm{msec}$ in Experiment 2A). Thus, at least two elements seem to constitute the effectiveness of accessory stimuli. One such element could be a stimulus-driven, bottom-up response facilitation effect that would tend to speed up responding regardless of contingencies. We conceptualize this bottom-up part as a type of arousal effect, produced by any accessory energy, which adds an increment to signal strength. Most likely, this bottom-up part also accounts for the finding that responding is generally more forceful in trials with accessory tones than without accessory tones.

The other element is dependent on contingencies, and thus would tend to speed up responding more when the accessory is related to go responses than when it is related to no-go responses. This element can explain the pattern of effects on both response speed and response force in Experiment 1 , where accessory stimulation speeded up responding more when it was more frequent with go than with no-go responses, whereas it increased response force more when it was more frequent with no-go than with go responses. These contrasting effects on response speed and response force in Experiment 1 can be accounted for by an extension of the "motor readiness" model proposed by Näätänen (1971). This model assumes a fixed motor-action limit and a variable level of motor activation. After the level of motor activation exceeds the limit, an overt response is executed. 
The critical value that determines RT and response force in this model is the distance between the limit and the level of motor readiness before the response signal was detected. This distance reflects the increment of motor activation needed to trigger a response, and both RT and response force tend to increase with the size of this distance. Mattes et al. (1997) suggested that low-probability responses require a larger increment in response activation to reach the motor-action limit than do high-probability responses. Concurrently, the overshoot in motor activation is larger for low-probability responses than for high-probability ones, because the amount of overshoot increases with the amount of increment; thus, low-probability responses are executed more slowly and forcefully. Applied to our experimental setting, an accessory stimulus influenced the amount of motor readiness, depending on whether it was contingently presented with go or no-go responses. If accessory tones were more frequent in no-go trials, detection of the accessory tone would cause a decrease of motor readiness, thereby increasing the necessary increment in response activation for go responses. Conversely, if accessory tones were more frequent in go trials, detection of the accessory tone would cause an increase of motor readiness and would decrease the necessary increment in response activation.

This extended motor readiness model fits well with the hypotheses of Hackley and Valle-Inclán $(1998,1999)$ and Posner et al. (1976). To account for the effects on response speed and response force, the distance between the level of motor readiness and the motor-action limit is crucial. Accessory tones might influence this distance, either because they increase the level of motor readiness, or because they decrease the motor-action limit. Regardless of the exact nature of these adjustment processes, the model's predictions remain the same.

\section{Accessory Stimulation and Redundancy Gain}

Concerning the impact of accessory stimulation on the size of redundancy gain, the observed data pattern is unclear. Experiment $2 \mathrm{~A}$ replicated the recent finding of Miller and Van Nes (2007) that redundancy gain is reduced by the presence of an accessory stimulus. In contrast, accessory tones had no clear impact on redundancy gain in Experiments 1 and 2B. ${ }^{3}$ Overall, then, it seems likely that accessory stimuli have only a small —and, therefore, statistically hard to detect - effect on redundancy gain.

More importantly, the absence of a stimulus-related contingency effect on redundancy gain is somewhat unexpected. Interstimulus contingency manipulations do produce strong effects when contingencies between target stimuli are varied (e.g., Miller, 1991, Experiment 2; Mordkoff \& Yantis, 1991), as can be explained by certain models of interstimulus contingency processing (e.g., Mordkoff \& Yantis, 1991). Because interstimulus contingencies between targets and irrelevant accessories have no impact, in contrast, it appears that mechanisms sensitive to interstimulus contingencies are insensitive to irrelevant accessory stimuli; this fits well with the conclusion of response-level effects of these stimuli.

\section{AUTHOR NOTE}

This research was supported by a grant of the G. A. Lienert Foundation to A.K. and by a grant from The Marsden Fund administered by the Royal Society of New Zealand. Correspondence concerning this article may be addressed to A. Kiesel, Department of Psychology, University of Würzburg, Röntgenring 11, 97070 Würzburg, Germany (e-mail: kiesel@psychologie.uni-wuerzburg.de) or to J. Miller, Department of Psychology, University of Otago, Dunedin, New Zealand (e-mail: miller@psy.otago.ac.nz).

\section{REFERENCES}

Abrams, R. A., \& Balota, D. A. (1991). Mental chronometry: Beyond reaction time. Psychological Science, 2, 153-157.

Balota, D. A., \& Abrams, R. A. (1995). Mental chronometry: Beyond onset latencies in the lexical decision task. Journal of Experimental Psychology: Learning, Memory, \& Cognition, 21, 1289-1302.

Bernstein, I. H. (1970). Can we see and hear at the same time? Some recent studies of intersensory facilitation and reaction time. Acta Psychologica, 33, 21-35.

Bernstein, I. H., Rose, R., \& Ashe, V. (1970). Preparatory state effect in intersensory facilitation. Psychonomic Science, 19, 113-114.

Bertelson, P., \& Tisseyre, F. (1969). The time course of preparation: Confirmatory results with visual and auditory warning signals. Acta Psychologica, 30, 145-154.

Corballis, M. C. (2002). Hemispheric interactions in simple reaction time. Neuropsychologia, 40, 423-434.

Diederich, A., \& Colonius, H. (2004). Bimodal and trimodal multisensory enhancement: Effects of stimulus onset and intensity on reaction time. Perception \& Psychophysics, 66, 1388-1404.

DoYLe, M. C., \& SNOWDEN, R. J. (2001). Identification of visual stimuli is improved by accompanying auditory stimuli: The role of eye movements and sound location. Perception, 30, 795-810.

DufFT, C., \& UlRich, R. (1999). Intersensorische Erleichterung: Auch visuelle Begleitreize können die Reaktionszeit verkürzen. Zeitschrift für Experimentelle Psychologie, 46, 16-27.

Fernandez-Duque, D., \& Posner, M. I. (1997). Relating the mechanisms of orienting and alerting. Neuropsychologia, 35, 477-486.

Giray, M., \& Ulrich, R. (1993). Motor coactivation revealed by response force in divided and focused attention. Journal of Experimental Psychology: Human Perception \& Performance, 19, 1278-1291.

Gondan, M., Niederhaus, B., Rösler, F., \& Röder, B. (2005). Multisensory processing in the redundant-target effect: A behavioral and event-related potential study. Perception \& Psychophysics, 67, 713-726.

Hackley, S. A., \& Valle-Inclán, F. (1998). Automatic alerting does not speed late motoric processes in a reaction time task. Nature, 391, 786-788.

HaCKLEY, S. A., \& VALLe-InClán, F. (1999). Accessory stimulus effects on response selection: Does arousal speed decision making? Journal of Cognitive Neuroscience, 11, 321-329.

HACKLEY, S. A., \& VALle-InClán, F. (2003). Which stages of processing are speeded by a warning signal? Biological Psychology, 64, $27-45$.

Hershenson, M. (1962). Reaction time as a measure of intersensory facilitation. Journal of Experimental Psychology, 63, 289-293.

Keuss, P. J., Van der Zee, F., \& Van den Bree, M. B. (1990). Auditory accessory effects on visual processing. Acta Psychologica, 75, 41-54.

Kiesel, A., Miller, J., \& Ulrich, R. (2007). Systematic biases and Type I error accumulation in tests of the race model inequality. Behavior Research Methods, 39, 539-551.

Mattes, S., UlRich, R., \& MilleR, J. (1997). Effects of response probability on response force in simple RT. Quarterly Journal of Experimental Psychology, 50A, 405-420.

Miller, J. (1982). Divided attention: Evidence for coactivation with redundant signals. Cognitive Psychology, 14, 247-279.

MiLler, J. (1986). Timecourse of coactivation in bimodal divided attention. Perception \& Psychophysics, 40, 331-343.

MiLlER, J. (1991). Channel interaction and the redundant-targets effect 
in bimodal divided attention. Journal of Experimental Psychology: Human Perception \& Performance, 17, 160-169.

Miller, J., Franz, V., \& Ulrich, R. (1999). Effects of auditory stimulus intensity on response force in simple, go/no-go, and choice RT tasks. Perception \& Psychophysics, 61, 107-119.

Miller, J., \& VAN NES, F. (2007). Effects of response task and accessory stimuli on redundancy gain: Tests of the hemispheric coactivation model. Journal of Experimental Psychology: Human Perception \& Performance, 33, 829-344.

MordKoff, J. T., \& Miller, J. (1993). Redundancy gains and coactivation with two different targets: The problem of target preferences and the effects of display frequency. Perception \& Psychophysics, 53, 527-535.

MordKoff, J. T., \& Yantis, S. (1991). An interactive race model of divided attention. Journal of Experimental Psychology: Human Perception \& Performance, 17, 520-538.

NÄÄTÄNEN, R. (1971). Non-aging foreperiods and simple reaction time. Acta Psychologica, 35, 316-327.

NAKANO, Y. (1997). Intersensory facilitation in a go/no-go and a choice reaction time task. Tohoku Psychologica Folia, 56, 14-21.

NaKano, Y. (2002). Transient and sustained effects of an auditory accessory stimulus in a visual go/no go task. Perceptual \& Motor Skills, 95, 599-605.

NICKERSON, R. S. (1973). Intersensory facilitation of reaction time: Energy summation or preparatory enhancement. Psychological Review, 80, 489-509.

NIEMI, P., \& NÄÄTÄNEN, R. (1981). Foreperiod and simple reaction time. Psychological Bulletin, 89, 133-162.

Posner, M. I., Nissen, M. J., \& KLeIn, R. M. (1976). Visual dominance: An information-processing account of its origins and significance. Psychological Review, 83, 157-171.

SANDERS, A. F. (1980). Stage analysis of reaction process. In G. E. Stelmach \& J. Requin (Eds.), Tutorials in motor behavior (pp. 331-354). Amsterdam: North-Holland.

Schmidt, R. A., Gielen, S. C., \& Van Den Heuvel, P. J. (1984). The locus of intersensory facilitation of reaction time. Acta Psychologica, $\mathbf{5 7}, 145-164$

SChröger, E., \& WidmanN, A. (1998). Speeded responses to audiovisual signal changes result from bimodal integration. Psychophysiological Research, 35, 755-759.

Shams, L., Kamitani, Y., \& Shimojo, S. (2000). What you see is what you hear. Nature, $\mathbf{4 0 8}, 788$.

Stahl, J., \& Rammsayer, T. H. (2005). Accessory stimulation in the time course of visuomotor information processing: Stimulus intensity effects on reaction time and response force. Acta Psychologica, 120, $1-18$
Stein, B. E., London, N., Wilkinson, L. K., \& Price, D. D. (1996). Enhancement of perceived visual intensity by auditory stimuli: A psychophysiological analysis. Journal of Cognitive Neuroscience, $\mathbf{8}$, 497-506.

TodD, J. W. (1912). Reaction time to multiple stimuli. Archives of Psychology, 3, 1-65.

Ulrich, R., \& Mattes, S. (1996). Does immediate arousal enhance response force in simple reaction time? Quarterly Journal of Experimental Psychology, 49A, 972-990.

Ulrich, R., Mattes, S., \& Miller, J. (1999). Donder's assumption of pure insertion: An evaluation on the basis of response dynamics. Acta Psychologica, 102, 43-75.

UlRich, R., MilleR, J., \& SCHRÖTER, H. (2007). Testing the race model inequality: An algorithm and computer programs. Behavior Research Methods, 39, 291-302.

Ulrich, R., Rinkenauer, G., \& Miller, J. (1998). Effects of stimulus duration and intensity on simple reaction time and response force. Journal of Experimental Psychology: Human Perception \& Performance, 24, 915-928.

Zeigler, B. L., Graham, F. K., \& Hackley, S. A. (2001). Cross-modal warning effects on reflexive and voluntary reactions. Psychophysiology, 38, 903-911.

\section{NOTES}

1. When varying contingencies, the term "irrelevant" is no longer appropriate, from a strict information-theoretical viewpoint. However, from the point of view of the instructions to the participants, the accessory stimuli are irrelevant.

2. A reanalysis of the data of Experiments 1 and $2 \mathrm{~A}$ also renders this suspicion unlikely. Subdividing the data sets into first and second halves of the experiment did not reveal any changes in the contingency effects as a result of practice. That is, the contingencies in Experiment 1 were learned very quickly, because they were apparent already in the first experimental half. In contrast, in Experiment 2A, the contingency manipulation did not produce any influence on the impact of accessory stimulation in either the first or in the second half.

3. In Experiment 1, the accessory tone descriptively had an impact on redundancy gain: Redundancy gain amounted to $22 \mathrm{msec}$ with an accessory tone and $29 \mathrm{msec}$ without, although the interaction did not reach significance $[F(2,44)=2.19, p=.135]$. In Experiment $2 \mathrm{~B}$, redundancy gain was not influenced at all by accessory stimulation, as it amounted to $21 \mathrm{msec}$ with an accessory tone and $21.5 \mathrm{msec}$ without.

(Manuscript received December 6, 2005; revision accepted for publication March 12, 2007.) 